\title{
Sutureless aortic valve replacement in combined procedures: Check whether there is room for the new guy before inviting them
}

\author{
John Bozinovski, MD, MSc
}

\author{
From the Division of Cardiac Surgery, University of British Columbia and the Royal Jubilee Hospital, Victoria, \\ British Columbia, Canada. \\ Disclosures: Author has nothing to disclose with regard to commercial support. \\ Received for publication Jan 6, 2018; accepted for publication Jan 12, 2018; available ahead of print Feb 28, 2018 \\ Address for reprints: John Bozinovski, MD, MSc, 106-2020 Richmond Rd, Victoria V8R-6R5, British Columbia, \\ Canada (E-mail: john.bozinovski@ubc.ca). \\ J Thorac Cardiovasc Surg 2018;155:2423-4 \\ $0022-5223 / \$ 36.00$ \\ Copyright (C) 2018 by The American Association for Thoracic Surgery \\ https://doi.org/10.1016/j.jtcvs.2018.01.030
}

It is not uncommon that mitral valve disease, sufficient to warrant consideration of intervention, occurs concomitantly with aortic valve disease. ${ }^{1}$ Whether combined valve intervention is undertaken is affected by many factors related to the valve, patient, and operative team. The report from Baran and colleagues ${ }^{2}$ regarding sutureless-aortic valve replacement (SU-AVR) in multiple valve operations touches on these. Our colleagues in Ankara describe SUAVR in 30 patients undergoing concomitant mitral valve repair $(n=8)$ or replacement $(n=22)$. The authors conclude that SU-AVR is safe and reliable in multivalve surgery but requires vigilance when selecting recipients, the type of mitral prosthesis, and the technique for implantation of the aortic and mitral prostheses.

It may be that the shorter ischemic time afforded by SUAVR does not translate to improved outcomes, although there is an implication that it does, especially in longer, more complex operations. ${ }^{3}$ The report by Baran and colleagues $^{2}$ does not suppose to answer that question definitively because there was no group for comparison. Indeed, it is unclear from which patient population the 30 patients were drawn. Over the duration of time from which the 30 combined valve procedures occurred, the authors report having performed a total of 149 combined valve procedures. However, the seeming benefit of the SU-AVR may have emboldened them to offer more complex operations to patients who otherwise might have only received isolated conventional AVR or isolated mitral valve replacement (MVR), leaving the secondary valve alone. Thus, the 30 patients were not necessarily drawn from the combined valve procedure cohort of 149 patients.

Among the strengths of the article is the finding that at 1 year paravalvular leak was less than mild, providing some reassurance that paravalvular leak is not a significant concern in combined SU-AVR/mitral valve procedures. As well, the authors have shown that a concomitant mitral valve procedure is not prohibitive to the use of an SUAVR. However, patient and prosthesis selection is

\section{References} $677-84$.

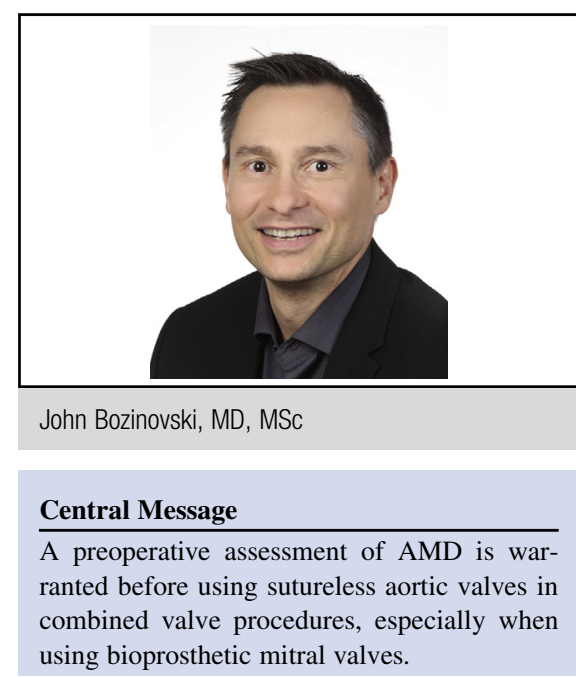

See Article page 2414.

important. Of the 22 cases in which MVR was undertaken, 3 patients $(14 \%)$ required explantation and reimplantation because of initial supra-annular positioning of the SU-AVR. These 3 patients had biologic MVR $(21 \%$ of the biologic MVR recipients). The 8 patients with a semirigid annuloplasty ring and the 8 patients with mechanical MVR had no need for revisions. Although the authors cautioned on the use of SU-AVR in patients in whom the aorto-mitral distance (AMD) was less than $5 \mathrm{~mm}$, they did not comment on the measured AMD in the 3 patients who required SU-AVR revision. Because all patients with an AMD less than $5 \mathrm{~mm}$ had mechanical MVR, it seems the supra-annular positioning occurred despite having an AMD greater than $5 \mathrm{~mm}$. This suggests an even greater AMD is needed for biologic MVR with SU-AVR or risk suboptimal deployment $20 \%$ of the time. Reimplantation of the valve would certainly expend any saving of ischemic time the SU-AVR intended on providing. They suggest computed tomography to assess AMD and guide decisionmaking. In summary, make sure there is room for the new guy before inviting them in.

1. Lee R, Li S, Rankin JS, O’Brien SM, Gammie JS, Peterson ED, et al. Fifteen-year outcome trends for valve surgery in North America. Ann Thorac Surg. 2011;91: 
2. Baran C, Durdu MS, Gamus F, Cakici M, Inan MB, Sirlak M, et al. Sutureless aortic valve replacement with concomitant valvular surgery. J Thorac Cardiovasc Surg. 2018;155:2414-22.
3. Pollari F, Santarpino G, Dell'Aquila AM, Gazdag L, Alnahas H, Vogt F, et al. Better short-term outcome by using sutureless valves: a propensity-matched score analysis. Ann Thorac Surg. 2014;98:611-7. 